'llu. Revista de Ciencias de las Religiones

ISSN: $1135-4712$

http://dx.doi.org/10.5209/ILUR.61024

\title{
De herejías, blasfemias, proposiciones y "malas palabras". Una caracterización de los pecados de palabra en el pensamiento teologal (siglos XVI a XVIII)
}

\author{
Rogelio Jiménez Marce ${ }^{1}$
}

Recibido: 7 de noviembre de 2017 / Aceptado: 12 de abril de 2018

Resumen. En el trabajo se presenta una caracterización de los pecados de palabra, es decir, aquellas transgresiones en las que predominaba la oralidad, a fin de entender cuál era el lugar que se les asignaba dentro de un orden normativo que tendía al control de las actividades de los individuos y la razón por las que se les perseguía. Se muestra, en un primer momento, cuáles fueron las modificaciones del pensamiento cristiano que permitieron realizar clasificaciones específicas de los pecados, pues a raíz de la emergencia del tomismo, y el predominio de una ética sustentada en el Decálogo, se comenzó a hablar de pecados de palabra, pensamiento, obra y omisión. En la investigación también se presentan los mecanismos que la Iglesia Católica utilizó para controlar el uso de la palabra. Se buscaba tener un estricto control de la palabra para evitar que se propagaran ideas erróneas, ideas que podían quebrantar el edificio doctrinal y el sistema de creencias. La libertad de pensamiento, la duda o la incredulidad no eran permisibles en un esquema que buscaba imponer su visión del mundo, y que, por lo mismo, no podía permitir la disensión o el cuestionamiento de sus paradigmas.

Palabras clave: pecado de palabra, herejía, mentira, control social, denuncia.

\section{[en] Of heresies, blasphemies, propositions and "bad words". A characterization of the sins of the word in theological thinking ( $16^{\text {th }}$ to $18^{\text {th }}$ centuries)}

\begin{abstract}
At work a characterization of the sins of word, i.e., those transgressions in which predominated orality, to understand what was the place that was assigned occurs within a legal framework that tended to control activities individuals and the reason why he was persecuted. At first, it shows what modifications of Christian thought that allowed for specific classifications of sins were, as a result of the emergence of Thomism, and the predominance of an ethical supported by the Decalogue, he began to speak of sins in thought, word, and deed. In researching the mechanisms that the Catholic Church used to control the use of the word they are also presented. The aim was to have strict control of the word to avoid misconceptions, ideas that could break the building and doctrinal belief system from spreading. Freedom of thought, doubt or disbelief were not permissible in a scheme that sought to impose their world view and, therefore, could not allow dissent or questioning of paradigms.
\end{abstract}

Keywords: word sin, heresy, lie, social control, denunciation.

Sumario: 1. Introducción. 2. El pecado y sus distintas clasificaciones. 3. Una clasificación de los pecados de palabra. 4. El control de la palabra. 4.1. Ayudar al prójimo: la corrección fraterna. 4.2. La

1 Instituto de Ciencias Sociales y Humanidades "Alfonso Vélez Pliego". Benemérita Universidad Autónoma de Puebla (México).

Correo electrónico: rojimarc@yahoo.com.mx. 
corrección judicial: denuncia y autodenuncia. 5. A manera de conclusión. 6. Bibliografía. 6.1 Archivos. 6.2. Fuentes impresas. 6.3. Referencias bibliográficas.

Cómo citar: Jiménez Marce, R. (2018), De herejías, blasfemias, proposiciones y "malas palabras". Una caracterización de los pecados de palabra en el pensamiento teologal (siglos XVI a XVIII), en 'Ilu. Revista de Ciencias de las Religiones 23, 129-147.

A mi querido sobrino Carlos Emanuel

\section{Introducción}

Con motivo de un coloquio que se realizó en Royaumont sobre herejías, y que reunió a un importante número de investigadores de la época, Jacques Le Goff mencionaba que los historiadores debían analizar con mayor atención este tipo de transgresiones, temática que se definía de forma "vaga" y "diversa", además de que existían dificultades para delimitar los espacios en los cuales se manifestaba ${ }^{2}$. Unos años después, Hilarie Belloc había advertido que el estudio de las herejías resultaba de particular interés, debido a que permitiría entender no sólo la historia europea sino también la manera en que se producían modificaciones en el pensamiento religioso, tanto de manera individual como colectiva, a consecuencia de la introducción de ideas que tendían a cuestionar y/o negar los principios en los que se sustentaba la doctrina ${ }^{3}$. Ha corrido mucha tinta desde aquel llamado. Los historiadores han dedicado numerosos estudios para analizar los factores sociales, políticos, religiosos y culturales de las herejías, y de otros tipos de "delitos verbales" que lo mismo podían cuestionar las verdades religiosas o convertirse en "sublevaciones verbales" de protesta en contra de las injusticias de la vida. Sin embargo, un asunto al que no se le ha prestado suficiente atención es la manera en que se construyó, desde el ámbito teológico, una clasificación de los pecados de palabra, mismos que agrupaban diversas tipos de transgresiones en las que predominaba la oralidad. Los teólogos fueron prolíficos en cuanto a la caracterización de los diferentes tipos de pecado de palabra, mismos que tenían distintas gradaciones pecaminosas y por lo mismo, los castigos variaban en función del tipo de transgresión que se cometía. La creación de una disciplina de la palabra tenía el objetivo no sólo de controlar lo que decían los individuos, sino también de incentivar el silencio como el comportamiento ideal del creyente, es decir, su deber ser. La profusión de afirmaciones incluidas en la clasificación de los pecados de palabra, daba cuenta de la necesidad de establecer límites acerca de qué se decía y quién lo hacía, pues la difusión de ideas erróneas podía causar interpretaciones equívocas que redundarían en la distorsión del conocimiento doctrinal cristiano, asimismo se buscaba establecer un orden social pues existían expresiones que podían contribuir a la desestabilización de las relaciones individuales y colectivas, tal como era el caso de las injurias.

\footnotetext{
Le Goff, 1987.
}

Belloc 1966, 15; Belloc 2007, 31.

4 Entre otros puede consultarse Burke 1987; Garrioch 1987; Madero 1992; McKnight 2000; Myers 2000; Lopez 2001; Claramitaro 2002; Nava 2004; Lipsett-Rivera 2005; Villa-Flores 2006; Albornoz 2007; Santana 2008; Escobar 2009; Ordorika 2009; Ricós 2013; Tabernero 2013; Ulloa 2013; Gelabertó 2014; Vauchez 2014; Almeida 2016; Castañeda 2016; Hamui 2016; Pérez 2016; Salazar, Velasco 2016; Silva 2016; Carranza 2016. 
En este trabajo se mostrará, en un primer momento, la forma en que se concibieron las primeras sistematizaciones de los pecados y las modificaciones que se realizaron en el pensamiento cristiano, sobre todo en el siglo XIII, que permitieron incluir codificaciones específicas de las transgresiones, entre las cuales se encontraban las de palabra. En un segundo momento, se presentara la tipificación de los pecados de palabra, a fin de entender las diversas categorías que se incluían en ella, la importancia que se le concedía a las herejías y a las blasfemias, y la manera en qué se les diferenciaba, situación que implicaba, en última instancia, un castigo específico de acuerdo a la profundidad de la falta. Por último, se expondrá cuáles eran las estrategias, tanto religiosas como judiciales, que se empleaban para controlar la palabra. Se recomendaba, en primera instancia, que los fieles recurrieran a la corrección fraterna para reconvenir a aquellas personas que realizaban afirmaciones erróneas, pero si esta estrategia fallaba entonces se debía denunciar ante las autoridades judiciales, única forma en que, según se decía, se podría garantizar la salvación del infractor. Las numerosas denuncias que se resguardan en archivos judiciales, como el del Santo Oficio de la Inquisición, evidenciaban que los individuos se volvían diligentes censores de las actividades sociales, sobre todo en aquellos casos que existían transgresiones del pensamiento religioso.

\section{El pecado y sus distintas clasificaciones}

A lo largo de la historia del cristianismo, se han establecido diversas clasificaciones de los pecados que ponían de manifiesto las modificaciones en la calificación sociomoral de los actos humanos. Las exigencias morales reflejaban los cambios que se experimentaban en los esquemas culturales y simbólicos ${ }^{5}$. La gestación de los pecados de palabra fue un proceso complejo que cristalizó hasta el siglo XIII. En la tradición bíblica se mencionan tres pecados capitales: la avaricia, el orgullo y la concupiscencia. Escritores como Cipriano, Orígenes, Cirilo de Alejandría y Macario mencionaban tres faltas graves: la apostasía, el adulterio y el homicidio; en tanto que Tertuliano lo reducía a dos: las graves (blasfemia, mentira, fraude y fornicación) y las ligeras. Por su parte, Prudencio Clemente hablaba de una "psychomaquia" o lucha entre virtudes y pecados ${ }^{6}$, vinculación que derivaba de los esquemas binarios del pensamiento grecorromano, mismos que serían desplazados por los pluralistas, como sucedió con Evagrio que identificaba ocho pecados capitales (gula, lujuria, avaricia, ira, tristeza, acidia, vanagloria y soberbia). Por su parte, Agustín identificaba dos tipos de pecados: los graves y los pequeños, idea retomada por Cesáreo de Arles quien realizó una precisión: los "crimina capitalia" correspondían a los pecados graves, en tanto que los pequeños carecían de importancia.

La propuesta de Cesáreo inspiró la clasificación de Gregorio Magno, quien estableció que había siete pecados capitales, clasificación acorde al pensamiento de la época que postulaba la existencia de siete sacramentos y siete dones del espíritu santo $^{7}$. A comienzos del siglo XII, Anselmo de Canterburry planteó que los pecados eran voluntarios y de ignorancia, distinción retomada por Pedro Abelardo, los victo-

\footnotetext{
Ricoeur 1981, 190, 300; Soto 2006, 414.

La psicomaquía tuvo vigencia hasta los siglos XIV y XV. Sebastián 1992, 43.

Le Goff 1989, 103, 135, 259; Minois 1994, 54, 160, 227-229.
} 
rinos, Guillermo de Champeaux e Yves de Chartres, quienes coincidían en que existía una relación entre pecado e ignorancia y entre intención y conducta, con lo que adquirió mayor énfasis el acto penitencial y se establecieron las bases para diferenciar los pecados mortales de los veniales. Aunque en siglos anteriores se había hecho una distinción entre pecados leves y graves, tal como sucedió con Atton de Verceil que identificaba pecados venialia y pecados capitales, a partir del siglo XII, y gracias a los esfuerzos intelectuales de los portéanos, se mostraría la diferencia existente entre los pecados mortales y veniales. Como el pecado venial era el único digno de venia, la concepción del pecado adquirió un sesgo jurídico-espiritual pues la suerte eterna se determinaba en función de la gravedad de las transgresiones ${ }^{8}$. Dos aspectos adquirieron importancia: la distinción entre vicio y pecado y entre falta y pena. La falta se podía redimir mediante la contrición y la confesión, la pena mediante la satisfacción de una penitencia ordenada por la iglesia.

La noción de responsabilidad se enriqueció con las ideas desarrolladas por Pedro Abelardo acerca del adentro y del afuera, mismas que sirvieron como sustento de la lógica de la intención que determinaba la calificación de la obra más que la acción. La reflexión interna de los pensamientos y deseos suponía un yo consciente, con lo cual la intención se convirtió en el fundamento de la confesión. La persecución del pecado se inscribió en el ámbito de la interiorización y personalización de una vida moral que reclamaba nuevas prácticas penitenciales. En el sistema moral tradicional, construido en torno a los siete pecados capitales, se entendía que éstos representaban la exposición negativa del doble mandamiento de Jesús de amar a Dios y al prójimo ${ }^{9}$. En este sistema moral existía un amplio repertorio de clasificaciones septenarias, las cuales aportaban una serie de categorías que permitían a los cristianos identificar las pasiones de hostilidad como opuestas al cristianismo. Las tipificaciones tenían la desventaja de reducir las obligaciones hacia Dios y de no tener ninguna autoridad bíblica que las sustentara, situación que se modificó en el siglo XIII cuando los teólogos construyeron una ética cristiana sustentada en el Decálogo que modificó la definición de los pecados.

La implantación de los Mandamientos como la base del sistema religioso originó una nueva serie de inculpaciones. Entre las nuevas apreciaciones morales se encontraba la idea de encumbrar la posición del demonio, la idolatría se consideró la principal transgresión y el pecado mortal se tornó insalvable. El esquema de los siete pecados promovía una ética social y comunitaria en la que los pecados de hostilidad eran los más graves; en tanto que el del Decálogo hacía hincapié en una ética introspectiva e individualista ${ }^{10}$. Bajo este esquema moral, se construyó la clasificación to-

8 Delumeau 1973, 207, 211; Oyola1979, 32-33, 62, 81, 97; Le Goff 1989, 133, 245-246, 249; Minois 1994, 78, 175; Russell 1995, 12, 87.

9 Oyola 1979, 56, 64, 93, 127, 159; Le Goff, 1989, 394; Minois, 1994, 219-220; Pérez 1996, 154-155; Morgado 1997, 123; Aspell 2008, 431, 436.

10 Minois, 1994, 226; Cervantes 1996, 42; Cervantes 1997, 29, 144; Trevor-Roper 2009, 101-102. A medida que los diez mandamientos se establecieron como el sistema aprobado de la ética cristiana, la brujería y el demonismo se convirtieron en los enemigos que se debían destruir. La lucha contra la brujería suscitó una revaloración del maniqueísmo, pues se decía que Satanás no podía actuar sin el permiso de Dios. El máximo furor de la lucha contra la demonología y la brujería se produjo entre los siglos XVI y XVII. Este fenómeno, a decir de Hugh Trevor-Roper, resultaba desconcertante, pues en el seno de una sociedad que se volvía sofisticada, en ámbitos como la ciencia o el pensamiento, se manifestaban, al mismo tiempo, las "pasiones más oscuras y las pasiones más inflamables" en los sectores más ilustrados. Así, por ejemplo, la persecución de la brujería fue promovida por "los papas cultos del Renacimiento, los grandes reformadores protestantes, los santos de la Contrarreforma, los eruditos, los hombres de leyes y los clérigos de la era de Scaliger". 
mista de los pecados que entendía al Decálogo como un compendio de la ley natural. Tomás de Aquino estableció tres categorías de pecados que guardaban correspondencia entre sí: los mortales o veniales; los pecados contrarios a Dios, al prójimo y a sí mismos; y los de pensamiento, palabra y obra que podían ser externos cuando se expresaban en acciones (palabras y hechos) e internos cuando se consumaba en la mente o en el corazón (pensamientos). Los pecados de obra eran más graves que los de palabra y los de palabra eran más graves que los de pensamiento. En los pecados de obra se manifestaba el apetito sensitivo y en los de palabra, la intencionalidad ${ }^{11}$.

Aquino decía que se debían considerar dos aspectos de la palabra: en sí misma y lo que expresaba. La palabra en sí no producía ningún daño, pero su sentido cambiaba cuando expresaba las ideas internas del individuo, es decir, cuando el sonido se tornaba "palabra humana". Para juzgar los pecados de palabra, se tenía que tener en cuenta quién la pronunciaba y los fines que perseguía. Por lo regular, estos pecados se producían por ligereza o por realizar juicios "temerarios" de las creencias divinas. Aunque muchos pecados de palabra no eran premeditados, se tenían que vigilar para evitar que un vicio menor se convirtiera en mayor. Así, por ejemplo, de la ira podía emanar la blasfemia que era un pecado mortal o la maldición que sólo era venial. Todos los pecados tenían correlación entre sí. Los de obra, palabra y pensamiento podían ser mortales o veniales y podían ser contrarios a Dios, al prójimo o contra sí mismo $^{12}$.

\section{Una clasificación de los pecados de palabra}

Los pecados de palabra se dividían en cinco grupos: los que procedían contra Dios, los que cuestionaban las estructuras jerárquicas de la sociedad, los que provocaban la deshonestidad, las que humillaban a los individuos, y las mentiras. En el primero se contaba la herejía, la superstición, la desesperación, la impaciencia, el falso juramento, el juramento execretorio, la idolatría, la presunción, la blasfemia, la maldición, el juramento vano, el perjurio, el sacrilegio, la contumelia, la irreligiosidad, las proposiciones y la irreverencia contra Dios. Estos pecados negaban el respeto al Creador al ponerse en duda su poder y sabiduría. Este grupo de pecados tenía una relación estrecha con los de pensamiento. En el segundo grupo se encontraban las palabras irreverentes contra la Iglesia, los ministros del culto, los monarcas y las estructuras de poder. El peligro de estos pecados residía en que cuestionaban el orden social impuesto por Dios, motivo por el cual se podía generar desconfianza, desobediencia, aversión, disturbios, escándalos y animosidad. El tercero se componía de las palabras deshonestas, los cuentos provocativos, el vaniloquio, las conversaciones profanas, los alardes de pecados, la difusión de pecados secretos, los chismes y los malos consejos. Estas transgresiones incitaban a las personas a pecar. El cuarto estaba integrado por la venganza, la burla, el falso testimonio, la alabanza de la maldad, el juicio temerario, el odio, la aspereza, la ofensa, las burlas, los chistes, la contradicción, la réplica inoportuna, la locución necia, la inconsideración, el juramento de venganza, el escarnio, el juramento con deseo de daño grave, la impruden-

Aquino 2000, 127, 158, 174, 200-202.

Aquino 2000, 216, 222-223, 226, 231. 
cia, la palabra indiscreta, la murmuración, el vituperio, la palabra ociosa, la autoalabanza y la falsa modestia. Estos contribuían a menoscabar la imagen de las personas ${ }^{13}$.

El quinto se refería a la mentira cuya intención era engañar, poner en duda o falsear la verdad. La mentira constituía uno de los mayores males del mundo, pues se le consideraba uno de los siete espíritus del engaño. La mentira no sólo era contraria a Dios sino que constituía un mal uso del lenguaje, pues se le daba una falsa significación a las palabras para perturbar el entendimiento. La utilización del lenguaje para engañar significaba una trasgresión a las intenciones divinas de proporcionar un medio de comunicación para el hombre, pues se decían cosas que contrariaban la verdad, tal como sucedía en las fábulas. La mentira ocasionaba un gran daño cuando se mentía en materia de religión o contra la religión, pues con ello se negaba la concepción de Dios como verdad e incentivaba el desorden y la maldad humana. La duda, la adulación, la charlatanería y la simulación constituían errores del habla humana, pero la mentira destruía los fundamentos de autoridad de la doctrina y comprometía la salvación eterna. Así, la mentira se convertía en una malicia privativa, es decir, un acto en el que el objeto no era acorde a la razón. Existían tres tipos de mentiras: la jocosa (la que se hacía por recreación), la oficiosa (la que buscaba una utilidad propia o ajena) y la perniciosa (la que tenía la intención de causar daño). Una mentira se tornaba grave cuando causaba daños a un tercero como el juramento con mentira, la alabanza de los objetos, las promesas incumplidas y las afirmaciones sin sustento. La mentira grave se volvía herejía cuando se negaba el pecado de fornicación, se incurría en la usura o no se pagaban los diezmos. La mentira era leve cuando se refería a la falsedad sin necesidad como la excusa o la negación de hechos ocurridos, aunque ésta se volvía grave cuando se ocultaba la verdad por vergüenza, miedo o para causar daño, debido a que se perseveraba en el pecado, se privaba a la justicia y se hacía sufrir al inocente ${ }^{14}$.

La mentira generaba que las personas perdieran el crédito, la autoridad y la buena opinión ante los demás, además de que contribuía a la destrucción de la caridad, la benevolencia y la comunicación, pues se decía una cosa con las palabras y se sentía lo contrario en el interior, lo cual se denominaba restricción puremental. De acuerdo con los teólogos, los pecados de palabra más perjudiciales eran la herejía y la blasfemia, pues contenían una esencia maliciosa intrínseca que atentaba contra la divinidad. La primera se oponía a la virtud teologal de la fe, mientras que la segunda ponía en entredicho la esencia de Dios y la virtud de la religión. La herejía atentaba contra los mandamientos mientras que la blasfemia atribuía a Dios lo que no le convenía, se le negaba lo que le convenía y se le imputaba a la criatura lo que sólo a Dios convenía ${ }^{15}$. Se consideraba que existían cuatro tipos de blasfemias: la de razón del objeto que distinguía dos ámbitos: inmediato (si se atribuía a Dios una cosa indigna, si se negaban sus perfecciones, si se le maldecía, si se decían cosas vergonzosas sobre él y si se utilizaban palabras que lo deshonraban) y mediato (si se maldecía a la virgen (hiperdulía), a los santos (dulía) y al espíritu santo o si se burlaban de los bienaventurados); la de razón de modo y de obra podía ser de corazón (si era interna), de boca (si era de palabra o escrita) y de acción contumeliosa (escupir al cielo, pisar un cru-

13 Suma 1497, VIII, XLIII; Alamín, 1714, 434, 440, 453, 458, 464, 469, 473; Boneta 1718, 84; Corella 1734, 6466; Madre de Dios 1761, 164-165, 167; Ferrer 1848, 123-124, 127, 138, 140, 187-191.

14 Suma 1497, VII, XXXI, XLII, XLV; Alamín, 1714, 428; Ciencia 1730, 145, 157; Arciniega 1794, 340.

15 Alamín, 1714, 429-433; Corella 1734, 94; Catecismo 1779, 200; Ferrer, 1848, 122. 
cifijo o decir votos); la de razón de la intención que se clasificaba en diabólica (si tenía la intención de injuriar a Dios) y simple (si no la tenía); y la de razón de contenido era heretical (ataque o duda contra la fe), contumeliosa (injuria contra Dios) e imprecatoria (desear mal a Dios).

Las blasfemias eran palabras que contenían en sí mismas una culpa grave, pues atacaban el precepto de amar al creador. Para juzgar a los blasfemos, se debía tener en cuenta la "calidad" de los individuos: los de "baja condición social" debían ser regañados con aspereza, mientras que a los "respetables" se les debía tratar con templanza. Los teólogos decían que eran comunes dos tipos de blasfemos: los simples y los formales. Los primeros no se oponían a los artículos de la fe, por lo que su castigo debía ser menor debido a que no infringían las creencias. Lo contrario sucedía con los formales que contradecían los artículos de la fe y caían en la esfera de la herejía, aunque alcanzaban el perdón cuando aceptaban su penitencia. Los teólogos advertían que no se debía confundir la blasfemia con la herejía, pues la primera se situaba en el decir y la segunda en el creer. La blasfemia no impugnaba la existencia de Dios y podía considerarse un pecado venial por la imperfección de su acto. Sin embargo, la gravedad de las palabras determinaba que una blasfemia se convirtiera en un pecado mortal ${ }^{16}$.

La herejía se podía determinar por tres causas: si se oponía a un artículo de fe, si impugnaba un dogma y si se cuestionaba los libros canónicos. En todos los casos, la herejía se concebía como un punto de vista contrario a la enseñanza doctrinal. En el ámbito de la fe, el error y la herejía se podían considerar sinónimos. Para calificar a alguien como hereje se tenían que cumplir dos condiciones: que en su entendimiento se manifestaran errores respecto a la fe y que tuviera voluntad de aferrarse con tenacidad a su error. Había cuatro tipos de herejes: secretos o materiales, mixtos, parciales y formales. Los primeros eran aquellos cuyas palabras y comportamientos no manifestaban un apego tenaz a la herejía. Su posición era producto de un error del entendimiento causado por falta de instrucción, ignorancia, simplicidad o una mala enseñanza de los preceptos de la fe. En este caso, la herejía tenía un carácter interno y no requería castigo sino instrucción. Los mixtos concebían sus herejías en el pensamiento y las manifestaban a sus prójimos. La herejía mixta se dividía en dos tipos: manifiesta per se (cuando se hacía en público) y oculta per accidens (cuando se hacía en privado o de manera mental). A los mixtos se les imponían castigos leves por su desconocimiento doctrinal. Los parciales rechazaban las verdades de la fe sin anteponer ningún argumento. Esta herejía se identificaba con la apostasía ${ }^{17}$ y requería un castigo en función de sus afirmaciones.

Los herejes formales eran los que predicaban, defendían y seguían públicamente una doctrina que ponía en tela de juicio a la fe, además de que amenazaban con la subversión del cuerpo social. Esta herejía asumía dos formas: oculta cuando nadie o

16 Suma 1497, LXIII-LXIV; Alamin 1724, 445, 519; Corella 1734, 111, 118; Madre de Dios 1761, 169; Catecismo 1779, 177, 211; Arciniega 1794, 296; Concilio III 1859, 221; Cuarto Concilio 1898, 267; Guía s.p.i, 44; Eimeric 1983, 75-76. Otros pecados que compartían la condición maliciosa eran la desesperación, el odio a Dios, el juramento falso, los sacrilegios y la simple fornicación.

17 Andrade 1684, 67; Ferrer 1779, 266. Por apostasía se entendía tanto la negación como el abandono de la religión católica y la adopción de una distinta. Se decía que éste era uno de los peores pecados que se podían cometer y Dios lo castigaba con severidad. Aunque se decía que las herejía y la apostasía eran de la misma especie, se diferenciaban en cuanto la primera era una resistencia con pertinacia contra la fe mientras que la segunda se refería a resistir a algunas o todas las verdades de la fe de manera accidental. Ferrer indicaba que para el derecho canónico, la herejía comprendía a la apostasía sin ninguna diferenciación. 
pocos la conocían y pública cuando se manifestaba por palabra, por escrito o por señas. Los teólogos mencionaban que se debía destruir a la herejía, pues amenazaba la armonía de la sociedad cristiana. Como una herejía podía anidar en cualquier rincón de la pirámide social, los hombres se convertían en herejes en potencia. Una herejía se consideraba un grave delito contra la fe cuando se predicaban los errores, pues se creía lo falso y se negaba lo verdadero. Los fieles deberían evitar discutir con los herejes para evitar que sus falacias los engañaran y sólo debían desmentirlos aquellas personas versadas en materia doctrinal ${ }^{18}$. La extirpación de los pecados de palabra debía realizarla el confesor, quien determinaría las circunstancias en que se produjeron las afirmaciones para emitir su dictamen. Por ejemplo, las blasfemias, las recriminaciones contra Dios y las controversias se producían por causa de la ira; en ese caso, se debía evaluar si la proposición buscaba hacer daño o sólo fue producto de las circunstancias. Tampoco se podía reprimir las herejías pronunciadas en sueños, ni las que había dicho un niño o un viejo. Los teólogos advertían de la necesidad de reprimir los pecados de palabra, sin importar su naturaleza, debido a que éstos atentaban contra los dos primeros mandamientos y contra las virtudes teologales (fe, esperanza y caridad) ${ }^{19}$.

\section{El control de la palabra}

La tradición religiosa cristiana contaba con normas respecto a la forma en que debían hablar los fieles, a quienes se aconsejaba no perder el tiempo en pláticas inútiles, en dilucidar cuestiones dogmáticas o en expresar deseos impuros. Los teólogos reconocían la dificultad de lograr un control estricto de la palabra ${ }^{20}$, tarea necesaria en un sistema comunicativo en el que predominaba la oralidad, la cual se convertía en un medio de acción, debido a que la palabra contribuye a estructurar el mundo. Las palabras tienen la capacidad de darle sentido al acto y de configurar la unidad de validez en la que se desarrolla el intercambio de significados. El lenguaje no sólo es un instrumento de comunicación, sino también un efectivo medio de control. Como el lenguaje es una fuerza activa dentro de la sociedad, éste implica, en última instancia, una forma efectiva de actuar sobre los otros. El control de la comunicación verbal es una de las operaciones estratégicas de la construcción ideológica. El hombre es esencialmente palabra y quién tiene el control de ella adquiere poder. Desde el poder se acuerda quién puede hablar y de qué. Ese derecho se define como competencia, es decir, como el lenguaje de autoridad. Como no todos tienen derecho a expresar sus opiniones, el lenguaje se convierte en un instrumento de poder ${ }^{21}$. Sergio

18 Azpilcueta 1585, 54, 64, 190; Señeri 1695, 54,76-77, 80-81, 146-147; Concina 1766, 153; Arciniega 1794, 260262; Ceballos 2012, 58-68. La jerarquía eclesiástica consideraba que la represión de la herejía resultaba fundamental, en virtud de que no sólo alejaba del pensamiento canónico sino que también constituía una violación del bien común. La equiparación de los herejes con los infieles justificó la represión de aquellos que disentían de la ortodoxia cristiana. En el texto de Diana Luz Ceballos se encuentra una interesante reflexión de la manera en que se radicalizó la persecución de las herejías y de los herejes en el siglo XII.

19 Ferrer 1848, 119-120.

20 Catecismo 1779, 2; Eimeric 1983, 141.

21 Ricoeur 1981, 49, 52, 483; Foucault 1988, 12; Bellenger 1989, 30, 38-39; Burke 1996, 11, 14, 18, 38, 135, 163, 173. Burke señala que la aparición del "gobierno de la lengua" formaba parte de un movimiento general europeo que buscaba establecer mecanismos de autocontrol entre los individuos. Este movimiento nació bajo el amparo de algunas de las tendencias culturales y sociales que imperaban en la Europa del período moderno temprano, 
Pérez advierte que las prácticas verbales jugaron un papel primordial en la constitución y reproducción de la moral cristiana. El discurso cristiano había establecido modelos de conducta que guiaban la vida, pues la legitimidad del acto verbal ayudaba a la salud del alma ${ }^{22}$.

La implantación de una disciplina de la palabra sólo era comprensible en el marco de un sistema moral preocupado por controlar las afirmaciones de los individuos. Los teólogos consideraban que el hombre debía temerle a lo que salía de su boca, pues las malas palabras constituían un veneno para el oído ya que destruían la "pureza interior". Pérez señala que las "disciplinas de la palabra" expresaban un conjunto de reglas prácticas construidas en torno a dos aspectos: el examen de las circunstancias del uso de la palabra y una doctrina acerca del valor e importancia del silencio. En lo que se refiere al primer aspecto, se buscaba definir las condiciones del uso virtuoso del habla por medio del establecimiento de normas, modelos y prohibiciones destinadas a regular la conducta verbal. La segunda tenía una alta valoración, pues formaba parte de una actitud de moderación y humildad ${ }^{23}$. Como la palabra había provocado los males del mundo, los individuos debían permanecer callados. El silencio era una virtud que se debía cultivar, pues mostraba el control que se ejercía sobre sí y evidenciaba respeto a la divinidad. En éste se identificaban tres instancias: exterior que se refería al mutismo de las palabras y actos, interno que mostraba las potencias del alma, y divino que era la comunión con Dios ${ }^{24}$. El silencio era una virtud que debía ser cultivada de manera especial por las mujeres, pues con ello evidenciarían gravedad, reverencia, pudor y modestia.

El creyente no podía alcanzar la virtud cuando se dedicaba a hablar de "cosas vanas", "ligeras" e "inútiles". El hablar era una cualidad natural del ser humano. Después de que algo se concebía se formulaba en una expresión, lo cual explicaba porque la lengua se encontraba cerca del cerebro y la boca de la imaginación. Los confesores debían inculcar la mansedumbre entre los penitentes. Un pecado de palabra leve podía ser el causante de la muerte eterna, pues no se confesaba sino que se ocultaba en el corazón. Así, se debía ser prudente en la conversación, reprimir la palabra "inmoderada" y evitar la mentira. Cuando se debía hablar, primero se tenía que evaluar si no existía ningún afecto desordenado que causara daño, pues las palabras "deshonestas" incitaban a la concupiscencia o a la propagación de errores ${ }^{25}$. Un hombre podía callar cuando las pasiones no turbaban su entendimiento, el cual producía "buenas palabras" cuando era "sano", "templado" y "modesto". La difusión de ideas erróneas representaba un peligro, debido a que deformaban la verdad de la

tales como el Renacimiento y la Reforma. Los manuales de comportamiento aconsejaban abstenerse de hablar de ciertos temas. Así, las Instructions pour une jeune seigneur (1683), de Joachim Trotti de la Chetardye, recomendaba no hablar de política y religión pues eran temas que originaban disputas.

22 Pérez 1996, 158-161.

23 Pérez 1996, 163-164.

24 Escriva 1616, 103-104; Herrera 1617, 187; Alamín, 1714, 477; Boneta 1718, 314; Pinamonti 1734, 194; Concilio III 1859, 85; Foucault 1991, 68; Burke 1996, 158-159. Burke menciona que el silencio es uno de los elementos esenciales de las religiones. En el cristianismo se identifican tres tipos de silencio: deliberado, de la Iglesia y de la oración. Foucault señala que la cultura del silencio deviene del estoicismo que planteaba una relación en la que el maestro hablaba y el discípulo escuchaba. El silencio era una condición indispensable para adquirir la verdad. Aunque también se advertía del peligro que representaba el "silencio perpetuo" que constituía una "falsa persuasión".

25 Azpilcueta 1585, 52, 130; Herrera 1617, 627; Cruz 1681, 395; Señeri 1695, 147; Boneta 1719, IV; Guía s.p.i, 9 , 78-79, 81, 164; Aquino 2000, 221. 
doctrina y causaban daño en la conciencia de los fieles, pues no podían diferenciar lo falso de lo verdadero ${ }^{26}$. Los predicadores eran los únicos que podían comunicar el conocimiento verdadero. Aunque se debía castigar las palabras falaces, se aconsejaba tener mayor severidad con los que hacían afirmaciones de temas doctrinales. La sanción debía ser rigurosa en el caso de los religiosos y de los que utilizaba la Escritura para divertir al público o proferir obscenidades. Las palabras "falsas" representaban un pecado contra el Espíritu Santo y desvirtuaban la verdad contenida en las Escrituras. Los pecados de palabra nacían de la unión de la libertad con la voluntad, planteamiento que reproducía la idea de Tomás de Aquino relativa a que los actos humanos implicaban conciencia y libertad. Para que una acción se considerara pecaminosa debía ser voluntaria y libre. El consentir era un acto libre de la voluntad que no seguía los dictados de la razón ${ }^{27}$.

Los pecados de palabra comprendían las afirmaciones que amenazaban el control de la "palabra verdadera". Las afirmaciones incorrectas, las falsas proposiciones y las mentiras representaban una amenaza que se debía destruir, pues encarnaban un peligro contra la certeza inquebrantable de la doctrina y de la salvación. La gravedad de los pecados de palabra se medía con base en cuatro criterios: su objeto, su circunstancia, su duración y su intención ${ }^{28}$. Los teólogos afirmaban que existían varios modos para vencer los vicios de la lengua: abstenerse, desarraigar los afectos, el ayuno, las oraciones, las limosnas, santiguarse y los castigos corporales como arrastrar la lengua o llevar piedras en la boca como lo hacia san Pedro de Alcántara. En el ámbito personal, los fieles tenían la obligación de corregir los abusos de la lengua, pues ésta se les había proporcionado para alabar a Dios, obtener bienes temporales y espirituales, y para enseñar, corregir y consolar al prójimo. En este último sentido, la corrección fraterna resultaba fundamental para modificar aquellas conductas que no resultaban graves, pero también se debía proceder a la denuncia cuando así se requiriera. Estas dos estrategias se sustentaban en el juicio de autoridad para refrenar las malas palabras ${ }^{29}$.

\subsection{Ayudar al prójimo: la corrección fraterna}

La corrección fraterna se consideraba una amonestación caritativa del prójimo que podía ser secreta o con testigos. Ésta se consideraba uno de los cuatro preceptos de caridad hacia el prójimo, motivo por el que los fieles tenían la obligación de cumplirla para no cometer pecado de inadvertencia culpable (no ayudar al prójimo), de omisión del quinto mandamiento (no se aconsejaba al prójimo) y mortal (no se evitaba el pecado del prójimo). El fin último de la corrección era restituirle a Dios la honra que otros le arrebataban, pues las "malas palabras" evidenciaban menosprecio a la divinidad y los que incurrían en este pecado, establecían un vínculo con los condenados del infierno. Así, existían dos coros que denostaban a la divinidad: el terrenal formado por incrédulos, blasfemos, hechiceros, idólatras, mentirosos y herejes, y el del infierno. Para realizar la corrección fraterna debían concurrir tres circunstancias: tener la seguridad de que el pecado era mortal o venial peligroso, tener la esperanza de que el pecador se enmendaría, y el estado personal del transgresor. La corrección

26 Sánchez, 2015, 3. Se consideraba que la conciencia era la encargada de evitar las desviaciones o equívocos de la voluntad en su camino a la redención.

27 Aquino 2000, 248-252.

28 Escriva 1616, II; Corella 1734, 35, 63; Catecismo 1791, 323.

29 Suma 1497, VIII; Alamín 1714, 473, 482-483; Ferrer 1779, 318. 
se debía realizar sin importar si se dañaba la salud, fama y honra del pecador. Nadie debía abstenerse de corregir, aun cuando existiera la posibilidad de perder la vida o sus bienes temporales. El que hacía la corrección debía conocer la doctrina para ofrecer argumentos que desvanecieran el error y tener a su lado a personas confiables, pues hacerlo ante desconocidos podría generar angustia en el infractor ${ }^{30}$.

Enseñar al ignorante era una de las siete obras de misericordia y otorgaba gracias espirituales, debido a que se ayudaba a preservar el orden social. Pecar a solas estaba prohibido, pero, al final de cuentas, era un acto que no traspasaba las barreras de la responsabilidad individual, pero si el pecado invitaba a una infracción colectiva era evidente que se debía destruir. Si alguien se volvía un criminal por no avisar a las autoridades sobre un crimen, lo mismo sucedía con los individuos que no denunciaban o no corregían los pecados. Ellos se convertían en coautores del delito, pues era lo mismo tolerarlo con el silencio que fomentarlo con la obra. Condescender en un pecado era lo mismo que inducir a otro a pecar. Se debía hacer una increpación cuando las circunstancias así lo exigían, de lo contrario se daría el consentimiento a la frase expresada, el cual era directo cuando se complacía en el pecado e indirecto cuando no se resistía. De acuerdo con los teólogos, existían ocho formas por las que se podía consentir en un pecado: si se mandaba, si se aconsejaba, si se daba consentimiento, si se loaba, si se participaba, si se callaba, si no se impedía por palabra, obra o aviso y si no se manifestaba ${ }^{31}$.

Los fieles no corregían porque pensaban que sólo tenían obligación consigo mismos, lo cual no constituía una excusa válida pues una amonestación o una denuncia bastaban para hacerle un bien al prójimo. No ayudar al prójimo podía ocasionar la condenación eterna, pues era un pecado de omisión no cumplir con lo que marcaba el precepto y si había un voluntario consentimiento, la omisión se convertía en comisión. No se consideraba pecado cuando no se conocía el precepto o se estimaba que la acción no se podía realizar a causa de ciertas circunstancias. Los individuos que habían procurado aconsejar a sus semejantes a fin de que se alejaran de los pecados, garantizaban la salvación de su alma y libraban de la muerte eterna a los que habían ayudado. Sin embargo, la mayoría de los creyentes cometían pecados de omisión que sólo se borraban por medio de la penitencia. Si los teólogos ponían énfasis en los pecados de omisión, se debía a que, según ellos, los males del mundo se habían originado por este pecado. Otra forma que adoptaba el pecado de omisión en la corrección fraterna era la difusión de ideas erróneas, pues se ponía a los demás en pecado mortal sobre todo si realizaba por malicia. Si la causa del pecado era la ignorancia, la culpa se minimizaba aunque, en este caso, el pecado de omisión se debía eliminar por medio de la instrucción. Si el pecador se enmendaba, no había necesidad de denunciarlo ante las autoridades inquisitoriales ${ }^{32}$.

\subsection{La corrección judicial: denuncia y autodenuncia}

Cuando la corrección fraterna no funcionaba, el feligrés estaba obligado a proceder judicialmente en contra del infractor a través de la denuncia o en su caso, la autode-

30 Azpilcueta, 1585, 35; Andrade 1672, 102; Señeri 1695, 78, 147, 233; Alamin 1724, 91; Boneta 1718, 99; Catecismo 1779, 323; Catecismo 1791, 125; Arciniega 1794, 325-326.

31 Azpilcueta 1585, 63; Boneta 1718, 24-25, 279; Boneta 1719, 13; Ripalda 1808, 2.

32 Azpilcueta 1585, 196-200, 230; Escriva 1616, 37; Señeri 1695, 79, 149-150, 186; Aquino 2000, 201-202, 223. 
nuncia. Cuando la denuncia era espontánea se interrogaba sobre la naturaleza del delito. Se recomendaba poner atención en la herejía, pues si era de fuero interno y no se propagó el error, el inquisidor podía imponerle una pena menor y le amonestaría a permanecer firme en la fe; pero si los hechos no habían sido secretos, se procedía a registrar la declaración y se preguntaba cuántas personas habían conocido la herejía para aplicar las penas correspondientes. Si se trataba de una denuncia, el inquisidor ordenaba la presentación de testigos que eran interrogados bajo juramento y debía prestar atención a lo que decían, a fin de determinar si las afirmaciones fueron realizadas en broma o se hicieron en un tono terminante, pues sólo se procedería a la detención de un denunciado cuando se contaba con indicios suficientes ${ }^{33}$. Es importante mencionar que la dimensión moral del pecado se convirtió en un elemento clave para el control judicial de las acciones individuales. El individuo que cometía una infracción contra las normas provocaba una ruptura en el sistema de valores vigente. La interiorización de las reglas se convertía en el factor clave para lograr la homogeneidad de opiniones. Un individuo que conocía las reglas que regían a una sociedad podía conocer y reconocer cuando alguien las violaba.

La estrategia funcionó pues los fieles se convirtieron en fiscales de las malas acciones, tal como se constata en el hecho de que la mayoría de las denuncias inquisitoriales provenían de la gente común. No era necesario tener un sistema de policía cuando la misma población reconocía al enemigo que se encontraba en casa. Aunque se debe tener en cuenta que en muchas ocasiones, la relación que se establecía entre la denuncia y el delito no era la más adecuada, pues una rencilla o una mala interpretación podían sustentar la acusación. Las denuncias mostraban el compromiso que tenían las personas para preservar el orden social y ayudaban a valorar el conocimiento doctrinal del denunciante, quien se revelaba como un intermediario en la supresión de lo que consideraba una conducta desviada ${ }^{34}$. Las denuncias mostraban un cuerpo social vivo en el que los mecanismos de control social canalizaban la conducta y el pensamiento de los individuos. Los fieles consideraban que el pecado era una realidad que se debía enfrentar para garantizar la salvación del alma. Se reconocía que el pecado estaba inscrito dentro del orden del mundo y que en la debilidad de la humanidad se encontraba la raíz de todos los males ${ }^{35}$. Los pecadores eran agentes activos que amenazaban el orden natural y sagrado del mundo, debido a que se aislaban de la comunidad cristiana. Se consideraba que el diablo no sólo era la causa del mal sino la fuerza que unificaba a los pecadores en su guerra contra Dios. Convertir a los pecadores en siervos de Satán implicaba su deshumanización, misma que ayudaba a justificar su eliminación por ser los causantes de los desórdenes del mundo ${ }^{36}$.

La delación de los pecados se justificaba por el hecho de que la salvación de las almas era una empresa colectiva. Así, la denuncia se consideraba un acto heroico que se realizaba en nombre de la caridad, con lo que el denunciante efectuaba un acto virtuoso que contribuía a su perfeccionamiento; en cambio, el que ocultaba los pecados mostraba una "culpable indiferencia" y se volvía cómplice del pecador. Nadie debía hacerse participe de los pecados ajenos o mostrar indulgencia al infractor, aunque éste fuera un vecino, un amigo, un hermano o los padres. La sociedad entraba

33 Escriva 1616, 175; Herrera 1617, 848; Cruz 1681, 323; Señeri 1695, 54; Boneta 1718, 280-283; Vascones 1732, 32; Corella 1734, 96; Catecismo 1779, 323; Ferrer 1779, 536: Eimeric 1983, 126, 133-134, 140-142.

34 Dedieu 1980, 905; Martín 1992, 50; Rodríguez 1997, 158; Ceballos 2002, 312, 343-344.

35 Catecismo 1791, 271.

36 Delumeau, 1973, 53-54; Delumeau 2002, 42-43. 
en una dinámica en la que se debía delatar y se podía ser delatado, lo que no constituía una simple fórmula jurídica sino que era una tarea que se asumía con ahínco. Si la denuncia contra los pecadores se justificaba en tanto buscaba preservar el orden social, cómo se puede explicar el hecho de que los sujetos se autodenunciaran. La autodenuncia permite comprender dos aspectos: la forma en que los individuos asumían su culpabilidad y las consecuencias que podía traer el que otros denunciaran sus pecados. La autodenuncia revela los mecanismos empleados por el pensamiento teologal para constituir un escrupuloso sentimiento de culpabilidad en el sujeto. Ricoeur menciona que la culpabilidad se sitúa en tres planos: "ético jurídico" que reflexiona sobre la relación entre penalidad y responsabilidad, "ético religioso" que habla sobre la conciencia escrupulosa, y "psíquico teológico" que alude a una conciencia acusada.

La culpabilidad es una experiencia individual e interiorizada en la que el hombre aparece como el juez de sus propias acciones. Entender la culpabilidad desde esta perspectiva implica una experiencia ético-jurídica. El simbolismo jurídico de la culpabilidad trasciende el dominio público de la justicia penal para insertarse en el dominio privado de la conciencia moral. En este sentido, la culpabilidad agrega un tinte legal a lo moral con todas las restricciones que comporta la idea de "mens rea". El carácter restrictivo de la culpabilidad se deriva del vínculo que establece con la voluntariedad. El sentimiento de culpabilidad se sustenta en el conocimiento que el culpable tiene de sí, de forma que se vuelve una acusación sin acusador, un tribunal sin juez y un veredicto sin autor. Es una relación de alienación que lleva a que el hombre asuma el papel de juez en el tribunal de sus propias acciones ${ }^{37}$. La idea del tribunal como metáfora de la conciencia moral sirvió para sustentar la concepción religiosa del pecado. La culpabilidad necesita de una inculpación racional. En este punto, el examen de conciencia asume un papel de primera categoría. Es una mirada absoluta bajo la cual se realza la identificación del yo. El hombre adquiere responsabilidad de sí mismo y de sus trasgresiones. El proceso de autoconciencia implicaba una hermenéutica de sí mismo, es decir, una autointerpretación de las acciones realizadas, esto es lo que Foucault denomina como la "tecnología del yo", es decir, la forma en que el individuo actúa sobre sí mismo, a fin de transformarse y alcanzar cierto estado de felicidad, pureza o sabiduría ${ }^{38}$.

El pecado adquiere una dimensión real cuando se tiene conocimiento de la falta, pero no por ello se debe pensar que la culpabilidad es un sinónimo de ésta. La confesión reafirma el movimiento de interiorización de los pecados. Se deben reconocer las infracciones para que el sentido moral comience a operar. Lo que privaba en la confesión no era un proceso de perfeccionamiento, sino un temor generalizado sobre la presencia del mal en el individuo. La minuciosa esquematización de los pecados tenía la intención de perfeccionar el control sobre las acciones. La culpabilidad representa la expresión por excelencia de la conciencia y con ella aparece el hombre medida. El discernimiento del pecado se convierte en la medida de la culpa. Cuando se acentúa el yo de la confesión, la falta deja de ser percibida como pecado para convertirse en culpabilidad. Ésta encuentra sentido dentro de un esquema mental en el que el individuo está consciente de las acciones que decide realizar, las que pretende hacer y las que elige no llevar a cabo. Es un proceso en el que la libertad de

Ricoeur 1981, 127, 155, 258.

Foucault 1991, 98, 125. 
elección juega un papel preponderante, con lo cual el libre albedrío ocupa una posición esencial dentro de la visión ética del mundo. El espacio de manifestación del mal sólo aparece cuando se reconoce y se reconoce cuando se le acepta como una elección deliberada. Comprender que el mal es fruto de una elección significa que se reconoce la responsabilidad y las consecuencias que trae consigo.

La confesión del mal es condición de la conciencia de la libertad, pues el individuo se reconoce como el autor explícito del mal. El hombre culpable es consciente de que hizo mal uso de la libertad, lo que genera una disminución del valor del yo. El miedo constituye un vehículo de interiorización de la culpa, el cual se sitúa tanto en un ámbito físico como ético. El primero es el temor al castigo, mientras que el segundo representa el peligro de perder para siempre a Dios. Los dos tipos de miedo encuentran su sustrato en la incapacidad de vencer los imperativos del inconsciente. El individuo no siente peligro cuando la mente logra eliminar los elementos que le producen angustia, pero si sucede lo contrario entonces se considera que el castigo es la única forma en que puede enmendar las faltas. La autodenuncia permite acceder a la culpabilidad interior del hombre, pues los pecados ocultos sólo se podían conocer por el testimonio de los mismos pecadores. El examen de conciencia se convertía en un instrumento útil para determinar la dimensión pecaminosa de los pensamientos. Por lo anterior no debe extrañar que muchas autodenuncias tuvieran su origen en el confesionario. Para acrecentar el control de los individuos, se había determinado que ciertos pecados sólo podían ser absueltos por la Inquisición, razón por la que los individuos se presentaban ante ella para ser absueltos y mostrar la obediencia que debían a su confesor. Los métodos para lograr las autodenuncias eran tan eficaces que algunos individuos hacían un recuento pormenorizado de sus faltas presentes ${ }^{39}$ o pasadas ${ }^{40}$, lo que evidenciaba el éxito de la predicación sobre el pecado, pues su reconocimiento implicaba que se había logrado interiorizar las normas morales.

\section{A manera de conclusión}

El establecimiento de una serie de mecanismos para controlar el uso de la palabra muestra su importancia para el cristianismo. La Iglesia se detentaba como la portadora de la palabra verdadera y sólo unos cuantos eran los que tenían la autoridad de difundirla. Se necesitaba tener un estricto control de la palabra para evitar que se propagaran ideas erróneas, las cuales podían quebrantar el edificio doctrinal y el sistema de creencias. La libertad de pensamiento, la duda o la incredulidad no eran permisibles en un esquema que buscaba imponer su visión del mundo, y que, por lo mismo, no podía permitir la disensión o el cuestionamiento de sus paradigmas. La

39 Archivo General de la Nación (en adelante AGN), Inquisición, vol. 1319, exp. 22, f. 1. La minuciosidad que podía alcanzar una confesión se puede ver en el caso de Agustín de Vega, quien declaraba que "he dicho dos veces que es imposible que Dios este en la hostia como esta en el cielo y lo he creído. Yo he renegado cinco veces a la santísima trinidad, he renegado del patriarca san José cinco veces, del santo de mi nombre, del santo ángel de mi guarda y a toda la corte del cielo santo por santo y en presencia de muchos santos. Yo he maldecido el bautismo cinco veces con todo mi corazón, la hora en que nací, al padre que me bautizó, a mis padres, a todos los que a mi bautizo asistieron y las oraciones que dijeron".

40 AGN, Inquisición, vol. 1384, exp. 10, ff. 143. Por ejemplo, Josef Núñez se autodenunció por unos pecados que había realizado 20 años antes. 
palabra debía disciplinarse, es decir, restringirse a un orden establecido por la autoridad que determinaba quién y qué podía decirse. El autodominio de lo que se hablaba constituía una virtud que se debía fomentar, aunque se buscaba que el silencio se convirtiera en el deber ser del creyente. El papel del individuo era callar y limitarse a escuchar a los poseedores legítimos de la palabra, esto es, a los predicadores y confesores. No había otro camino en un sistema religioso que consideraba que la palabra era un mecanismo de perdición, tal como se puede corroborar en la pormenorizada manera en que se establecieron distinciones en las expresiones orales, que no sólo se referían a cuestiones doctrinales sino también de convivencia social. Si bien es cierto que los pecados de mayor relevancia eran aquellos que se referían a la religión, tales como la herejía o la blasfemia, no se puede pasar por alto el énfasis puesto en los que atentaban contra el orden social o los que incidían en el menosprecio de los individuos.

La utilización de la corrección fraterna daba cuenta del papel que la Iglesia otorgó a los individuos como delatores de los delitos de los demás, papel que permitió hundir las raíces del control social en los intersticios más profundos de la sociedad. El control de la palabra tenía sentido cuando se lograba penetrar en la cotidianeidad de los individuos, instancia en la cual se manifestaba y que evidenciaba la forma en que se había producido una naturalización discursiva del mundo social. Así, el discurso legítimo imposibilitaba la creación de sentidos diferentes y permitía identificar a los que lo cuestionaban. En este sentido, y como bien apunta José Antonio Escudero, no se perseguía a los que incurrían en pecado de palabra por lo que decían sino por el contenido de su discurso ${ }^{41}$, motivo por el cual, aunque en el archivo del Santo Oficio de la Inquisición de México se encuentran numerosos procesos en contra de aquellos que incurrían en pecados de palabra, son escasos los que culminaron con una condena debido a que la mayoría de las denuncias eran causadas por proposiciones o diversos tipos de blasfemias que no representaban una infracción grave. En última instancia, los pecados de palabra revelaban una insuficiente formación doctrinal y asimismo, ponían de manifiesto las tensiones de una sociedad que encontraba en las expresiones orales una manera de desahogar los conflictos internos, tanto a nivel individual como grupal. Aunque muchas de las denuncias de pecados de palabra podrían resultar insustanciales, tales como aquellas que referían que María no podía ser virgen o que el infierno no existía, lo cierto es que revelan el tipo de control que se ejercía sobre la sociedad y la manera en la que los individuos asumían el papel de censores de las conciencias de los demás y de sí mismo; con ello, se cumplía una de las metas de la rectitud, según lo explicaba Luis de Granada, que era "hazer virtud y cumplir con las obligaciones que el hombre tiene sobre sí" 42 .

\section{Bibliografía}

\subsection{Archivos}

Archivo General de la Nación. Fondo Inquisición

\footnotetext{
41 Escudero 2005, 55.

42 Sánchez, 2015, 3.
} 


\subsection{Fuentes impresas}

Alamín, F. de, 1724, Puerta de salvación y espejo de verdadera y falsa confesión, Madrid, Lorenzo Francisco Mojados.

- 1714, Falacias del demonio, y de los vicios que apartan del camino real del cielo, en que se descubren muchos engaños del demonio, con que oculta los caminos verdaderos y propone los falsos, y sus remedios generales y particulares, Madrid, Imprenta de Blas de Villanueva.

Andrade, A. de, 1684, Itinerario Historial que debe guardar el hombre para caminar al cielo dispuesto en treinta y tres grados, por los treinta y tres años de la vida de Christo Nuestro Redemptor, y las virtudes que en ellas exercitó, Barcelona, Imprenta de Josef Lopez.

- 1672, Viage para el cielo, breve y compendioso, conforme a la doctrina de Cristo nuestro redemptor, Madrid, Francisco Sanz.

Arciniega, M. de, 1794. Método práctico de hacer fructuosamente confesión general de muchos años, útil para confesores y penitentes por cuanto se proponen, y resuelven los casos más frecuentes que llegan al confesionario, Madrid, Imprenta de Ramón Ruiz.

Aquino, T. de, 2000, Tratado de la justicia, tratado de la ley, gobierno de los príncipes, México, Porrúa.

Azpilcueta, M. de, 1585, Manual de confesores y penitentes, Sevilla, Imprenta de Andrea Pescioni y Juan de León.

Boneta, J., 1719, Gracias de la gracia. Saladas agudezas de los santos. Insinuación de algunas de sus virtudes, ejemplos de la virtud de la eutrapelia, Pamplona, Alfonso Burguete.

- 1718, Gritos del infierno para despertar al mundo dedicada a quien esta en pecado mortal, Madrid, Viuda de Juan García Infançon.

Catecismo del santo Concilio de Trento para los párrocos ordenado por disposición de Pío $V, 1791$, Madrid, Ramón Ruiz.

Catecismo para uso de los párrocos hecho por el IV Concilio provincial mexicano celebrado en el año de 1771, 1779, México, Imprenta del licenciado Josef de Jáuregui.

Ciencia para las personas de corte, espada y toga, que escribió en francés Monsieur de Chevigni, traducida del idioma italiano en español y añadida en muchas partes por el Dr. J. B. C. S enriquecida, a más de las adiciones, con dos tratados de la física y retórica, 1730,Valencia, Imprenta de Joseph García.

Concilio III provincial mexicano, celebrado en México el año de 1585, confirmado en Roma por el Papa Sixto Vy mandado observar por el gobierno español en diversas reales ordenes, 1859, México, Eugenio Maillefert y Compañía editores.

Concina, D., 1766, Instrucción de confesores y penitentes, desengaño universal, que con toda claridad manifiesta el seguro camino del cielo, Madrid, Miguel Escribano, 1766.

Corella, J. de, 1734, Suma de la teología moral. Su materia, los tratados más principales de los casos de conciencia, su forma, unas conferencias prácticas, Madrid, Imprenta de Manuel Román.

Cruz, F. de la, 1681, Cuarta palabra credenda aplicada al purgatorio, Nápoles, Marco Antonio Ferrero.

Cuarto Concilio Provincial mexicano celebrado en la ciudad de México el año de 1771, 1898, Querétaro, Imprenta de la Escuela de Artes.

Eimeric, N., Peña, F., 1983, El manual de los inquisidores, Barcelona, Muchnik Editores.

Escriva, F., 1616, Discursos sobre los dos novísimos gloria e infierno muy útiles y provechosos para todos los estados y en particular para predicadores con dos tablas muy copiosas: una de los lugares de escritura y otra de las cosas notables, Valencia, Pedro Patricio Mey. 
Ferrer, V., 1779, Suma moral para examen de curas, y confesores que a la luz del sol de las escuelas Santo Thomas dio al público, Valencia, Francisco Burguete impresor del S. Oficio.

- 1848, Tratado de la confesión general para toda clase de personas, Barcelona, Imprenta de la Herederas de la V. Pla.

Guía para el cielo, s.p.i.

Herrera, A. de, 1617, Consideraciones de las amenazas del juicio y penas del infierno, Sevilla, Mathias Clavijo.

Madre de Dios, V., 1761, Fuero de la conciencia, Madrid, Andrés Ortega.

Pinamonti, P. J., 1734, El director de almas, método para dirigirlas por el camino de la perfección cristiana, Madrid, Antonio Sanz.

Ripalda, J. de, 1808, Catecismo y exposición breve de la doctrina cristiana con un tratado muy útil del orden con el que el cristiano debe ocupar el tiempo y emplear el día, Puebla, Imprenta de Pedro de la Rosa.

Señeri, P., 1695, El confesor instruido. Obra en la que se le muestra a el confesor nuevo la practica de administrar con fruto el sacramento de la penitencia y el penitente instruido, para confesarse bien, obra espiritual de la cual puede cualquiera aprender el modo de volverse a la gracia de su señor y de mantenerse en él, Madrid, Juan Joseph Guillén Carrascoso.

Suma de confessión llamada Defecerun de fray Anthonino, arzobispo de Florencia del orden de los predicadores en romance, s.p.i, 1497.

Vascones, A. de, 1732, Destierro de ignorancias, Madrid, Imprenta de Andrés Sánchez.

\subsection{Referencias bibliográficas}

Albornoz, M. E., 2007, "La injuria de palabra en Santiago de Chile, 1672-1822”, Nuevo Mundo Mundos Nuevos.

Almeida, J. B., 2016, "Dichoso vientre: palabras de injuria y devoción a la virgen María en la América protuguesa del siglo XVI", Carranza, C., Castañeda, R. (coords.), Palabras de injuria y expresiones de disenso. El lenguaje licencioso en Iberoamérica, México, 335-353.

Aspell, M., 2008, "El sacramento de la confesión. Los manuales y las sumas de confesión", Anuario del CIJS núm. IX, 2008, 431-437.

Bellenger, L., 1989, La persuasión, México.

Belloc, H., 1966, Las grandes herejías, Buenos Aires.

- 2007, “Qué es una herejía?”, La razón histórica núm. 1, 31-34.

Burke, P., 1996, Hablar y callar. Funciones sociales del lenguaje a través de la historia, Barcelona.

- 1987, The Historical Antrhropology of Early Modern Italy. Essays on perception and communication, Cambridge.

Carranza, C., 2016, "El castigo en verso. Aspectos de las maldición en la lírica popular hispánica, siglos XVI al XVII”, Carranza, C., Castañeda, R. (coords.), Palabras de injuria y expresiones de disenso. El lenguaje licencioso en Iberoamérica, México, 309-334.

Castañeda, R., 2016, "De reniegos e improperios medievales. La blasfemia entre los esclavos africanos y descendientes de la Nueva España, siglo XVII", Carranza, C., Castañeda, R. (coords.), Palabras de injuria y expresiones de disenso. El lenguaje licencioso en Iberoamérica, México, 201-221.

Cervantes, F., 1997, "El demonismo en la espiritualidad barroca novohispana”, García, G., Ramos, M., (coords.), Manifestaciones religiosas en el mundo colonial americano, México, 129-146. 
- 1996, El diablo en el nuevo mundo. El impacto del diabolismo a través de la colonización de Hispanoamérica, Barcelona.

Ceballos, D. L., 2012, "Política, Heterodoxia e Inquisición”, Historia y Sociedad núm. 22, 51-72.

— 2002. "Quyen tan hace que tal pague": sociedad y prácticas mágicas en el Nuevo Reino de Granada, Bogotá.

Claramitaro, F., 2002, "El Santo Oficio español y la herejía molinosista”, Contribuciones desde Coatepec núm 13, 21-60.

Dedieu, J. P., 1980, “Les archives de l'inquisition, source pour une etude anthropologique des vieux chretiens. Un exemple et quelques reflexions", J. Pérez (dir.), La Inquisición española. Nueva Visión, nuevos horizontes, Madrid, 893-912.

Delumeau, J., 1973, El catolicismo de Lutero a Voltaire, Barcelona.

— 2002, El miedo en Occidente (Siglos XIV-XVIII). Una ciudad sitiada, Madrid.

Escobar, K. L., 2009, “¿Del dicho al hecho hay mucho trecho? El delito de blasfemia en los tribunales de Cartagena y Lima. 1500-1700”, Fronteras de la Historia, vol. 14, núm. 1, pp. 13-39.

Escudero, J. A., 2005, Estudios sobre la Inquisición, Madrid.

Foucault, M., 1998, "El sujeto y el poder". Revista Mexicana de Sociología vol. L, núm. 3, 3-20.

- 1989, Tecnologías del yo y otros textos afines, Barcelona.

Garrioch, D., 1987, "Verbal Insults in Eighteenth Century Paris", Burke, P., Porter, R. eds., The Social History of Language, Cambridge, 104-109.

Gelabertó, M., 2014, "Mentes sacrílegas, palabras impías. Ateísmo y blasfemia en Cataluña, siglos XVI-XVIII”, 'Ilu. Revista de Ciencias de las Religiones núm. 19, 93-125.

Goff, J. Le, 1989, El nacimiento del purgatorio, Madrid.

- 1987, Herejías y sociedad en la Europa preindustrial (Siglos XI-XVIII), México.

Hamui, S., 2016, "Lo indecible de las palabras: códigos de los judaizantes en las cárceles secretas inquisitoriales novohispanas", Carranza, C., Castañeda, R. (coords.), Palabras de injuria y expresiones de disenso. El lenguaje licencioso en Iberoamérica, México, 173-199.

Lipsett-Rivera, S., 2005, "Los insultos en la Nueva España en el siglo XVIII”, Gonzalbo, P. (coord.), Historia de la vida cotidiana en México. III. Tradición y cambio, México, 473-500.

López, A. I., 2001, "Disidencia y poder en la Edad Media: la historia de los cátaros", Historia crítica núm. 20, 113-142.

Madero, M., 1992, Manos violentas, palabras vedadas: la injuria en Castilla y León, siglos XIII-XV, Madrid.

Martín, J. L., 1992, “Pecado y dominación feudal”, Pecado, poder y sociedad en la historia, Valladolid, 43-62.

McKnight, K. J., 2000, "La blasfemia como resistencia. Una esclava africana ante la Inquisición mexicana”, Giles, M. E. (ed.), Mujeres en la Inquisición. La persecución del Santo Oficio en España y el Nuevo Mundo, Barcelona, 228-306.

Minois, G., 1994, Historia de los infiernos, Barcelona.

Morgado, A., 1997, "Pecados y confesión en la España moderna. Los manuales de confesores", Trocadero. Revista de Historia Moderna y Contemporánea núms. 8-9, 119-148.

Myers, K, A., 2000, “¿Testimonio para la canonización o prueba de blasfemia? La Inquisición de Nueva España y la hagiografía de Catarina de San Juan", Giles, M. E. (ed.), Mujeres en la Inquisición. La persecución del Santo Oficio en España y el Nuevo Mundo, Barcelona, 326-356. 
Nava, V. G., 2004, ““Como era mentira/podía ser verdad'. Disparates en la lítica popular de los siglos XV a XVII: huellas de la cultura carnavalesca", Revista de Literaturas Populares, año IV, núm. 2, 271-287.

Ordorika, T., 2009, “HHerejes o locos?”, Cuicuilco núm. 45, 139-162.

Oyola, E., 1979, Los pecados capitales en la literatura medieval española, Zaragoza.

Pérez, R. S., 2016, "Los significados sociales de las injurias en la Nueva España, siglos XVI y XVII", Carranza, C., Castañeda, R. (coords.), Palabras de injuria y expresiones de disenso. El lenguaje licencioso en Iberoamérica, México, 89-121.

- 2008, "Por qué palabras duelen más que puñaladas. La injuria en Nueva España, siglos XVI y XVII", Fronteras de la Historia, vol. 13, núm. 2, 353-374.

Pérez, S., 1996, "La mentira y las disciplinas de la palabra en el mundo del pecado", Historia y grafía núm. 7, 157-179.

Ricoeur, P., 1981, Finitud y culpabilidad, Madrid.

Ricós, A., 2013, "De injurias y blasfemias, insultos y otros actos descorteses en los procesos inquisitoriales de los siglos XVI y XVII", Pérez, C., Tabernero, C. y Usunáriz, J. M. (eds.), Los poderes de la palabra: el improperio en la cultura hispánica del Siglo de Oro, Nueva York, 231-244.

Rodríguez, L. E., 1997, "Sentencia y penitencia: caminos hacia la reconciliación en la sociedad colonial", Fronteras núm. 1, 151-172.

Rusell, J. B., 1995, Lucifer. El diablo en la Edad Media, Barcelona.

Sebastián, S., 1992, "La iconografía del pecado", Pecado, poder y sociedad en la historia, Valladolid, 65-97.

Salazar, R., Velasco, J. A., 2016, "El honor mancillado. Injurias en la villa de San Gil (virreinato del Nuevo Reino de Granada) en vísperas de la independencia”, Carranza, C., Castañeda, R. (coords.), Palabras de injuria y expresiones de disenso. El lenguaje licencioso en Iberoamérica, México, 247-274.

Sánchez, I., 2015, "El rigor de la conciencia. Escrúpulos, disciplina y la ordenación de la república". Tiempos modernos vol. 30, núm. 1, 1-14.

Santana, M., 2004, El delito de blasfemia en el tribual inquisitorial de Cuenca, Alicante.

Silva, N., 2016, "La comunicación política y el animus injuriandi, en los reinos de las Indias: el lenguaje ofensivo como arma de reclamo y desprestigio del enemigo", Carranza, C., Castañeda, R. (coords.), Palabras de injuria y expresiones de disenso. El lenguaje licencioso en Iberoamérica, México, 13-57.

Soto, J. M., 2006, "Visión y tratamiento del pecado en los manuales de confesión de la Baja Edad Media Hispana”, Hispania Sacra vol. LVIII, núm. 118, 411-447.

Tabernero, C., 2013, "Presentación. El insulto como instrumento literario y social", Pérez, C., Tabernero, C. y Usunáriz, J. M. (eds.), Los poderes de la palabra: el improperio en la cultura hispánica del Siglo de Oro, Nueva York, 1-5.

Trevor-Roper, H., 2009, La crisis del siglo XVII. Religión, Reforma y cambio social, Buenos Aires.

Ulloa, G., 2013, "La blasfemia como resistencia en la canción Raza odiada”, Cuadernos Inter-c-a-mbio sobre Centroamérica y el Caribe, vol. 10, núm. 12, 149-173.

Vauchez, André, 2014, Les Hérétiques au Moyen Age. Suppots de Satan ou chrétienes dissidents, París.

Villa-Flores, J., 2006, Dangerous Speech. A Social History of Blasphemy in Colonial Mexico, Arizona. 
